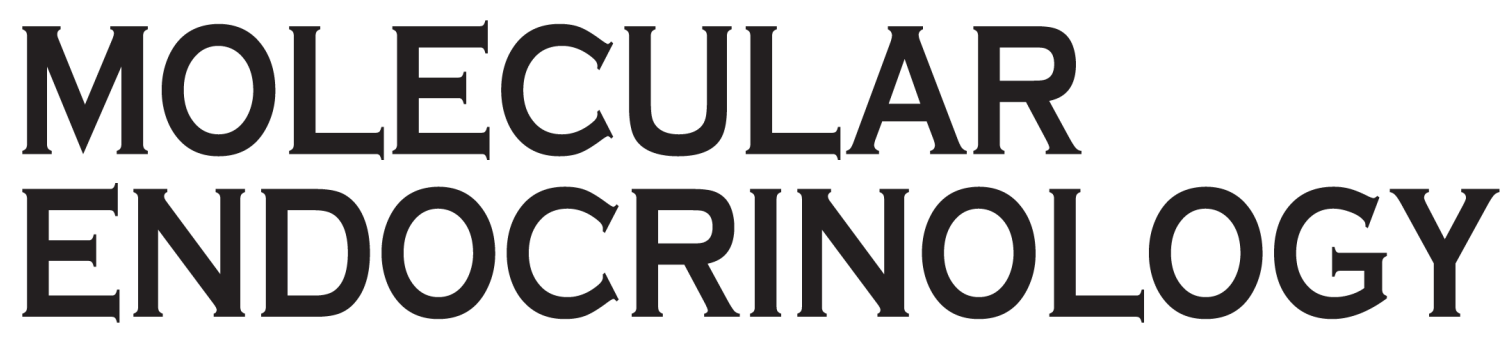

\title{
CAR, Driving into the Future
}

Karen Swales and Masahiko Negishi

Mol. Endocrinol. 2004 18:1589-1598 originally published online Feb 26, 2004; , doi: 10.1210/me.2003-0397

To subscribe to Molecular Endocrinology or any of the other journals published by The Endocrine Society please go to: http://mend.endojournals.org//subscriptions/
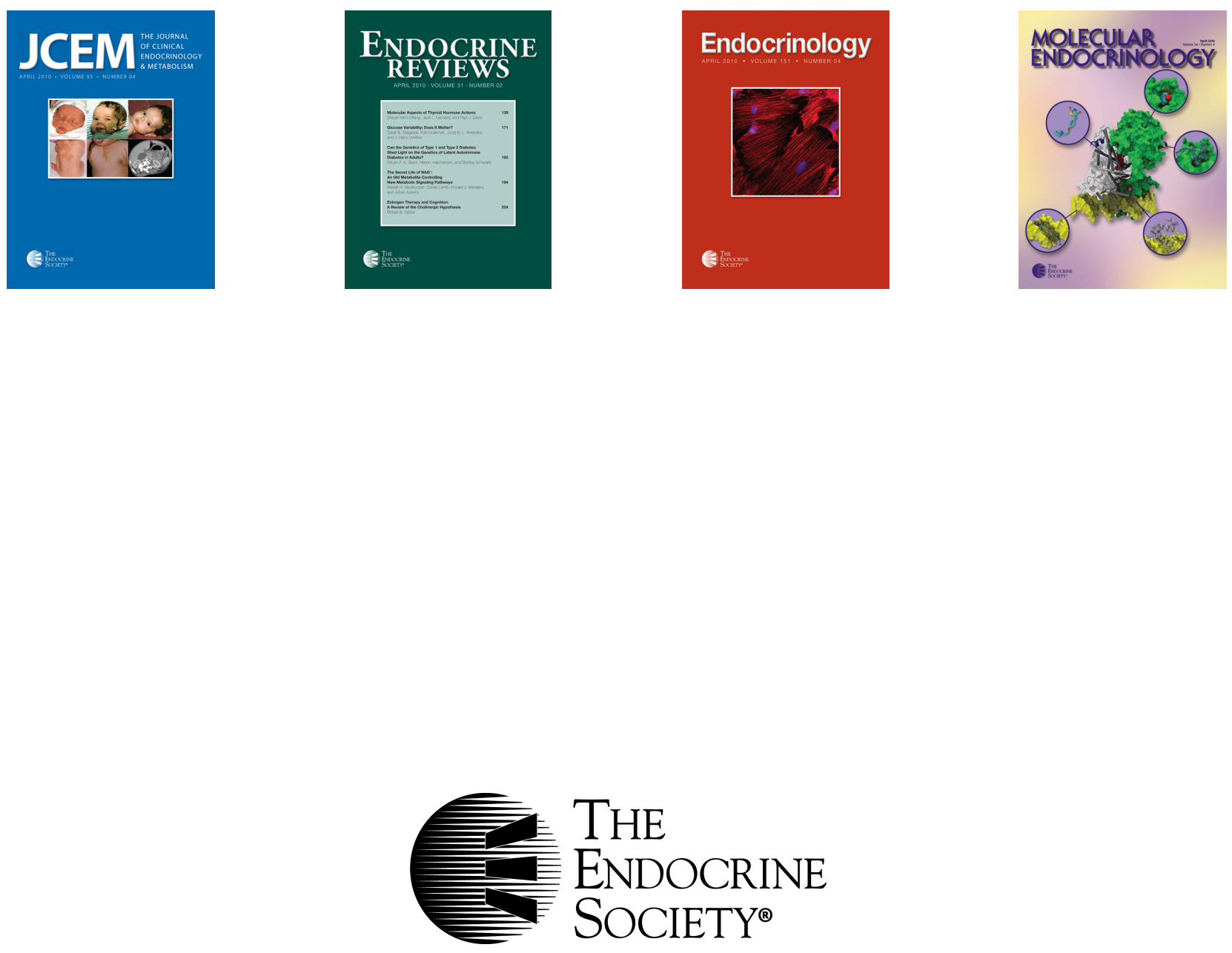


\title{
CAR, Driving into the Future
}

\author{
KAREN SWALES AND MASAHIKO NEGISHI \\ Pharmacogenetics Section, Laboratory of Reproductive and Developmental Toxicology, National \\ Institute of Environmental Health Sciences, National Institutes of Health, Research Triangle Park, \\ North Carolina 27709
}

The nuclear orphan receptor CAR is active in the absence of ligand with the unique capability to be further regulated by activators. A number of these activators, including phenobarbital, do not directly bind to the receptor. Considered a xenobiotic sensing receptor, CAR transcriptionally modifies the expression of genes involved in the metabolism and elimination of xenobiotics and steroids in response to these compounds and other cellular metabolites. Its hepatic expression pattern endows the liver with the ability to protect against not only exogenous but also endogenous insults. The mechanism of CAR activation is complex, involving translocation from the cytoplasm to the nucleus in the presence of activators, followed by further activation steps in the nucleus. Although this mechanism remains under investigation, we have summarized here the cellular signaling pathways elucidated so far and speculate on the mechanism by which CAR activators regulate gene expression through this network. (Molecular Endocrinology 18: 1589-1598, 2004)
W HEN A NOVEL HUMAN orphan nuclear receptor was cloned and named MB67 in 1994 (1), no one realized the impact it would have on the field of xenobiotic and steroid metabolism. This receptor, highly expressed in the liver, was capable of heterodimerizing with the 9-cis-retinoic acid receptor (RXR) and transactivating an empirical set of retinoic acid response elements in the absence of ligand (1). In 1997 a closely related mouse receptor with the same constitutive retinoic acid response element transactivation ability was identified, leading to the term constitutive activator of retinoid response (CAR) being coined (2), later shortened to constitutive active receptor for both mouse and human receptors. Subsequently, CAR has become best known for its ability to regulate induction of the CYP2B gene family by phenobarbital (PB) and PB-like inducers [e.g. chlorpromazine, phenytoin, dichlorodiphenyltri-

Abbreviations: AF2, Activation function 2; AhR, aryl hydrocarbon receptor; CAR, constitutive active/androstane receptor; CCRP, cytoplasmic CAR retention protein; CYP, cytochrome P450; FXR, farnesoid X receptor; GR, glucocorticoid receptor; GRE, glucocorticoid response element; GST, glutathione-S-transferase; Hsp, heat shock protein; LB, ligand binding; MRP, multidrug resistance-associated protein; NLS, nuclear localization sequence; NO, nitric oxide; $\mathrm{PB}$, phenobarbital; PBREM, PB-responsive enhancer module; PP2A, protein phosphatase $2 A$; PXR, pregnane $X$ receptor; SRC, steroid receptor coactivator; TCPOBOP, 1,4-bis[2-(3,5-dichloropyridyloxy)]benzene; UGT, uridine diphosphate-glucuronyl transferase.

Molecular Endocrinology is published monthly by The Endocrine Society (http://www.endo-society.org), the foremost professional society serving the endocrine community. chloroethane, 1,4-bis[2-(3,5-dichloropyridyloxy)]benzene (TCPOBOP) and polychlorinated biphenyls], thereby revealing its function as a xenobiotic-sensing nuclear receptor (3-5). The generation of CAR-null mice confirmed that CAR is essential for Cyp2b10 responses to $\mathrm{PB}$-like inducers $(6,7)$ and expanded the role of CAR in gene regulation by promoting the identification of numerous genes that are regulated by this receptor (7-11).

CAR generally binds to and activates transcription via DR4 motifs, such as the two nuclear receptor elements that flank the nuclear factor 1 site within the 51-bp PB-responsive enhancer module (PBREM) of Cyp2b10 $(4,12,13)$. The orphan nature of CAR generated a search for an endogenous ligand, especially in light of the receptor's apparent constitutive activity. Two androstane metabolites, $5 \alpha$-androst-16-en- $3 \alpha$-ol (androstenol) and $5 \alpha$-androstan- $3 \alpha$-ol (androstanol) were identified as CAR ligands but repressed the constitutive activity (14). Foresight was shown with the acronym CAR, which was then also applied to constitutive androstane receptor. In many ways CAR resembles a classic steroid hormone nuclear receptor such as the glucocorticoid receptor (GR), being retained in the cytoplasm until exposed to activators. However, the constitutively active nature of CAR and the fact that many of its activators including $P B$ do not bind directly to the receptor ${ }^{1}$ reflects a novel mechanism,

\footnotetext{
${ }^{1}$ Due to the complex nature of CAR regulation, in this review a ligand is defined only by its ability to bind directly to the receptor, whereas an activator or repressor is defined by its ability to modulate receptor activity without direct binding to the receptor. For example, TCPOBOP is considered both
} 
advances in the understanding of which will be examined herein.

Considering many CAR activators are xenobiotics, CAR (NR1/3) (15) joined its closest mammalian relative, the pregnane $X$ receptor (PXR, NR112) $(16,17)$, as a xenosensor (18). Since then, receptors related to the NR1I family have been identified in nonmammalian species: the chicken xenobiotic receptor and nhR8 in Caenorhabditis elegans $(19,20)$. This indicates that xenosensing activity is an ancient conserved function for this family, as the ability of nhR8 to contribute resistance to the toxins colchicine and chloroquine has been shown (20). In addition, the Xenopus benzoate $\mathrm{X}$ receptors $\alpha$ and $\beta$ (21), the teleost fish Fugu rubripes fr078207 (22), and the Drosophila HR98 (23) are closely related to the NR1I family. However, their role in xenosensing activity has hitherto been controversial or unconfirmed. The majority of these nonmammalian receptors resemble PXR more closely than CAR (22), suggesting that CAR may be a mammalian receptor that diverged from PXR at a later point in evolution. Although CAR is most frequently identified as a xenobiotic-sensing receptor, it may also have a role in endocrine homeostasis, because it regulates enzymes that metabolize xenobiotics, which are also involved in the metabolism of endogenous signaling compounds such as steroid hormones. Given the caveat that CAR exhibits species differences, this review focuses primarily on the role, function, and activation mechanism of mouse CAR.

\section{THE HEPATOTOXIC ROLE OF CAR}

CAR coordinates the regulation of multiple genes resulting, in most cases, in the net clearance of compounds from the blood by transporters such as organic anion transporter protein 2 and their metabolic detoxification within the hepatocyte by cytochrome P450s (CYPs), NADPH-cytochrome P450 reductase, and transferases. For example, sleep induced by PB was prolonged in CAR null mice (Fig. 1). Similarly, the muscle relaxant zoxazolamine resulted in paralysis in wild-type mice that was avoided by pretreatment with CAR activators but was prolonged in CAR knockout mice (6). Thus, CAR-coordinated induction of metabolic activity increases elimination of these drugs in a protective manner. The induction of 5-aminolevulinic acid synthase 1 by PB suggested that CAR also coordinates the induction of heme biosynthesis to accommodate increased CYP levels; however, induction studies with PB and TCPOBOP in CAR null mice indicate that 5 -aminolevulinic acid synthase 1 regulation is independent of CAR $(7,8)$. CAR can repress the genes that encode enzymes involved in signal transduction, fatty acid oxidation, and/or energy metabolism, e.g. phosphoenolpyruvate carboxykinase 1 , enoyl coen-

a ligand and an activator, whereas PB is only an activator due to its indirect activation mechanism.

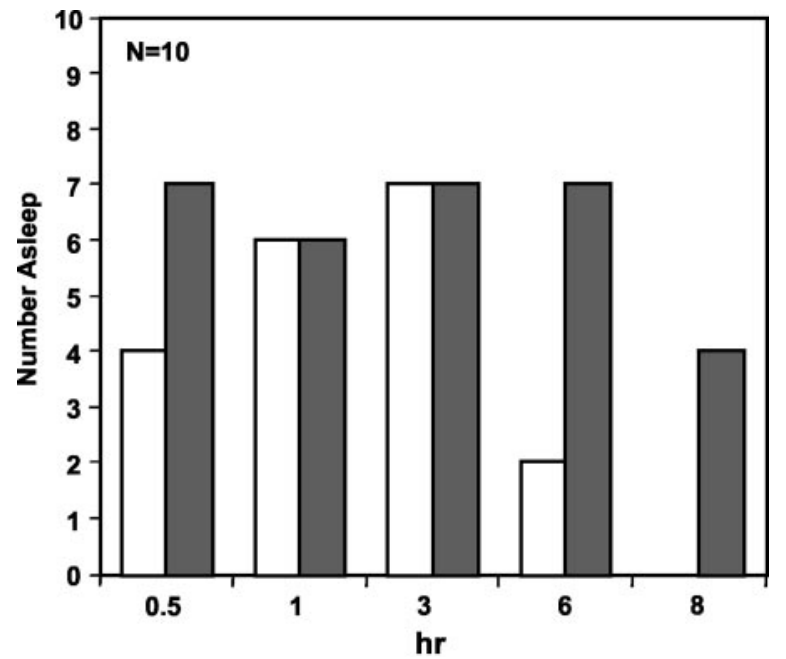

Fig. 1. PB-Prolonged Sleep in CAR-Null Mice

Male $\mathrm{C} 3 \mathrm{H}$ (open bars) and CAR-null (shaded bars) mice ( $n=10$ in each group; mean weight, $26 \pm 5 \mathrm{~g}$ ) were ip injected with $100 \mathrm{mg}$ PB per kg body weight at 0 and $24 \mathrm{~h}$ to examine the effect of PB on its own metabolism. From the time of the second injection, sleep duration was recorded as the time when the mice were able to right themselves.

zyme A isomerase, and carnitine palmitoyl transferase 1 (7). Repressing such physiological processes may provide a further mechanism for cells to cope with toxicity. CAR hepatoprotective action includes blockage of the induction by PB of certain genes, which were identified by their induction in only CAR null mice. For example CAR prevents the induction of CYP4A, the major microsomal lipid peroxidase, by $\mathrm{PB}$ and coordinately mediates the induction of superoxide dismutase 3 , which together may suppress oxidative stress (7). This CAR-mediated defense system against chemical toxicity is as applicable to endogenous as to xenobiotic compounds and may have evolved to deal with both.

\section{CAR as a Protective Factor}

Bilirubin, an oxidative end product of heme catabolism, is one of the most toxic natural breakdown products in the body. Accumulation is associated with jaundice that can chronically lead to neurotoxicity and eventually fatal encephalopathy $(24,25)$. Glucuronidation by uridine diphosphate-glucuronyl transferase UGT1A1 is the major detoxification pathway of bilirubin, and the conjugate is secreted across the bilecanicular membrane of hepatocytes into the bile by an active transporter multidrug resistance-associated protein (MRP) 2. For a long time it has been known that PB can decrease elevated bilirubin levels. This is now revealed to be due to the ability of CAR to activate the expression of known components of the bilirubin pathway including UGT1A1, organic anion transporter protein 2, MRP2, and glutathione-S-transferase (GST)A1 (25). CAR can activate the 290-bp gtPBREM (-3483/ 
-3194) in the UGT1A1 gene (24). Originally, two DR4 and one DR3 elements (named NR4, gtNR1, and NR3, respectively) were localized in the gtPBREM, of which gtNR1 provided the major CAR binding and activation site, although the other two sites were also required for optimal gtPBREM activity. Later, an additional DR3 element was found immediately downstream of NR4 within the gtPBREM to which both CAR and PXR could bind (26). Although this DR3 was implicated in PXR activation by rifampicin, it remains to be determined whether this is the primary site conferring rifampicin responsiveness to the UGT1A1 gene. The gtPBREM may be a general DNA sequence regulating the response to various xenobiotics as well as endogenous compounds, because it also contains an active aryl hydrocarbon receptor (AhR) binding site (27). It has been claimed that CAR further promotes bilirubin excretion by inducing the biliary transporter MRP2 in rodent hepatocytes $(25,28)$. Yet lack of significant MRP2 induction by CAR activators infers that the role of CAR is unclear $(29,30)$. An additional biliary transporter MRP3, with overlapping substrate specificity to MRP2, is also PB inducible, but PB induction of MRP3 appears to be CAR independent (31). Thus the role of CAR in regulating these MRPs is not clear. The defensive role of CAR includes protection against bile acid toxicity in the absence of key bile acid sensors farnesoid $X$ receptor (FXR) and PXR as shown in FXR PXR double knock out mice in which cholic acid elevated the levels of CAR and CYP2B mRNA, and pretreatment with $\mathrm{PB}$ or TCPOBOP induced a collection of target genes, incorporating those involved in protection against bilirubin toxicity, which reduced serum bile acid and bilirubin concentration (32). Thus CAR acts to complement FXR and PXR to coordinate protection against hepatic bilirubin acid toxicities.

\section{CAR as a Risk Factor}

This defense against toxicity, by increasing metabolism, may often promote the toxicity it purports to prevent. CAR was identified recently as a key regulator of acetaminophen metabolism and hepatotoxicity (33). In addition to the well-known GSTs that are induced by PB, CAR also regulates GSTPi, the enzyme that enhances glutathione depletion and so promotes acetaminophen toxicity (33-36). High-dose acetaminophen-induced toxicity occurred in wild-type but not CAR null mice (33), consistent with the resistance to this toxicity in GSTPi null mice (36). Similarly, CAR activators PB and TCPOBOP sensitize mice to cocaine hepatotoxicity, which is absent in CAR null mice (6). Nitric oxide (NO) may protect cells from such xenobiotic-induced toxicity by its antioxidant properties, which are able to terminate lipid peroxidation and oxidative stress. CAR regulates the human-inducible NO synthase gene via a DR4 element (37). However, prolonged exposure to NO will shift the cellular redox state to one more oxidized, via oxidation of thiols such as glutathione. Thus, chronic CAR activation may promote hepatotoxic effects.

\section{THE EXTRAHEPATIC ROLE OF CAR}

In addition to liver, CAR is also highly expressed in the epithelial cells of small intestine villi, where it was essential for the modest induction of Cyp2b10 by TCPOBOP and PB observed by Wei et al. (6, 9). However, a previous study showed lack of CYP2B10 induction in the intestine by PB (38). As CAR acts as a xenosensor to protect from exogenous insults, its expression at a point of entry into the body is reasonable. Clinical studies of orally administered drugs demonstrate that intestinal drug metabolism can significantly reduce oral bioavailability (39). Thus, CAR-mediated induction of Cyp2b10, phase II GSTs $\mu 1$ and $\theta 1$, and the broad specificity efflux pump Mdr1a in the intestine may enhance first-pass metabolism of xenobiotics. CAR is also expressed at low levels in both mouse and human heart, skeletal muscle, brain, kidney, and human lung $(1,2)$, but the physiological role of the receptor in these tissues has not been investigated thoroughly, especially in kidney where the CAR target gene Cyp2b10 is not expressed (38).

\section{CAR IN ENDOCRINE HOMEOSTASIS AND DISRUPTION}

CAR and other xenosensors, such as PXR, may form a regulatory network that governs endocrine homeostasis by altering hormone metabolism. The first endogenous modifiers of CAR activity identified were the steroids androstanol and androstenol, which inhibit the constitutive activity of the receptor by directly dissociating the interaction between CAR and the steroid receptor coactivator SRC-1 (14). Similarly, progesterone and testosterone repress constitutive CAR activity (40), but at greater concentrations than the circulating adult levels $(41,42)$. In contrast, pharmacological levels of active estrogens estradiol $\left(E_{2}\right)$ and estrone and the progesterone metabolite pregnane 3,20-dione can activate rodent and human CAR, respectively, above their constitutive levels $(40,43)$. Whereas in male mice experiments indicate that endogenous androgen may repress CAR transcriptional activity $(40,44)$, the physiological relevance of steroid hormone regulation of CAR activity, especially in humans, remains to be resolved.

As CYP2B, a major target for CAR activation, metabolizes both estrogen and androgen and CARregulated UGT1A1 glucuronidates estrogens, induction of these enzymes due to CAR activation by xenoand endobiotics could increase steroid hormone catabolism $(24,40,45,46)$. Sulfation is catalyzed by sulfotransferases (47) that are generally reported as 
noninducible by PB in humans and mice, although Maglich et al. (48) observed that newly identified human CAR activator 6-(4-chlorophenylimidazo[1,1-b] $(1,3)$ thiazole-5-carbaldehyde O-3,4-dichlorobenzyl)oxime (CITCO) induced human sulfotransferase 1A1 mRNA in one of three samples examined. However, CAR may augment steroid sulfation in the presence of PB by transactivating the $3^{\prime}$-phosphoadenosine 5'-phosphosulfate synthase 2 gene (7), which is responsible for synthesis of the biological sulfate donor 3 '-phosphoadenosine $5^{\prime}$-phosphosulfate (49). Thus, xenobiotics, through CAR, may influence the different stages of steroid hormone homeostasis by inducing the CYPs and transferases involved in the metabolism of estrogens and their precursor steroids.

Further evidence that CAR may be involved in steroid hormone metabolism came when a distal glucocorticoid response element (GRE) was identified in the human CAR gene, $4.4 \mathrm{~kb}$ upstream of the transcription start site, which was conserved in the murine CAR gene (50). The GRE consists of two imperfect GRE half-sites separated by three nucleotides (GGAACAacaAGGGCA) to which GR homodimers can bind (50). This provides a mechanism for the CAR induction previously observed by submicromolar concentrations of dexamethasone in primary human hepatocytes (51, 52), the potentiation of CYP2B2 and CYP2B10 induction by $\mathrm{PB}$ in the presence of dexamethasone in rats and mice, respectively $(53,54)$, and the fact that GR was found to be essential for dexamethasone-induced CYP2B expression (55). CAR, being a primary glucocorticoid receptor-response gene, adds a further level of complexity to endocrine homeostasis.

\section{REGULATORY MECHANISMS OF CAR ACTIVATION}

The mechanism of CAR activation is novel. In contrast to most orphan nuclear receptors that reside in the nucleus, CAR is compartmentalized in the cytoplasm in a manner similar to classic steroid hormone nuclear receptors such as GR (12). Retention in the cytoplasm prevents chronic activation of CAR target genes and allows tight regulation of the receptor's activity. Activators either bind directly to CAR, consistent with other family members, or act indirectly, such as PB and bilirubin, which do not bind to the receptor but translocate CAR to the nucleus, making translocation an initial step in the CAR activation process $(12,25$, 56). A phosphorylation cascade is involved in regulating CAR translocation, yet elucidation of the CAR activation mechanism has proved difficult due to the fact that CAR accumulates spontaneously in the nucleus of transformed cell lines regardless of activation state (12). A protein capable of retaining CAR in the cytoplasm of transformed cell lines has now been identified (57), expanding the possibilities for future research. Moreover, it has become apparent that translocation alone does not determine CAR activation, but that additional regulation is required in the nucleus. Investigations from our laboratory and those of others lead us to propose the following mechanisms for CAR activation (Fig. 2).

\section{Structural Aspect of CAR}

CAR is characterized by high constitutive activity in cell-based transfection assays. In computer-generated models CAR contains the conserved activation function 2 (AF2) domain and a standard ligand binding (LB) cavity lined with hydrophobic residues, supporting the ability of this receptor to bind specific ligands such as androstanol, TCPOBOP, and CITCO $(48,58-$ 61). The ability of CAR to respond to activators that do not directly bind to the receptor infers regulation by other means such as phosphorylation, yet the $\mathrm{N}$ terminal ligand-independent function 1 (AF1) domain that is associated with such regulation in other receptors is shortened in CAR to only 10 and 20 amino acid residues in the mouse and human receptors, respectively. Choi et al. (2) showed that mouse CAR lost constitutive activity after AF2 deletion or mutations (Leu352Ala or Glu355Ala). Thus, CAR appears to maintain its AF2 domain in an active conformation that facilitates interactions with coactivators in the absence of ligand, whereas LB binding optimizes the position of the AF2 domain for further coactivator recruitment $(14,43,58,62)$. Yet the question remains: how does CAR maintain the AF2 domain in an active conformation in the absence of ligand? Recent $x$-ray crystal structures of five different CARs in which the AF2 domains are in the active conformation provided structural interpretations of their activities (63-68). Moreover, the LB cavity is filled by an unexchangeable fatty acid in the hepatocyte nuclear factor $4(63,65)$ or is tightly packed with bulky residue side chains in the estrogen-related receptor ERR $\gamma(64)$ and nuclear-related receptor Nurr1 (68) structures, respectively. On the other hand, a rigid extended helix 2 appears to constrain the AF2 domain into the active conformation in liver receptor homolog-1, whereas the receptor's large LB cavity remains empty (67). Activation of the Drosophila Nurr1 homolog DHR38 is dependent on a preactivated heterodimerization partner and on ecdysteroids, which are too large to fit into the LB cavity (66). This activation mechanism remains to be clarified but may aid explanation of the LB-independent activation of CAR, although CAR forms a nonpermissive heterodimer with RXR. Accordingly, none of the current $\mathrm{x}$-ray crystal structures, when compared with computer-generated models of CAR, are easily adopted to explain the constitutive activity of the receptor. Uniquely, despite its constitutively active nature, CAR is tightly regulated in vivo in liver, thus conferring responsiveness to activators.

Although a broad range of structurally dissimilar xenobiotics and endogenous compounds can modulate CAR constitutive activity, it is known that mutation 


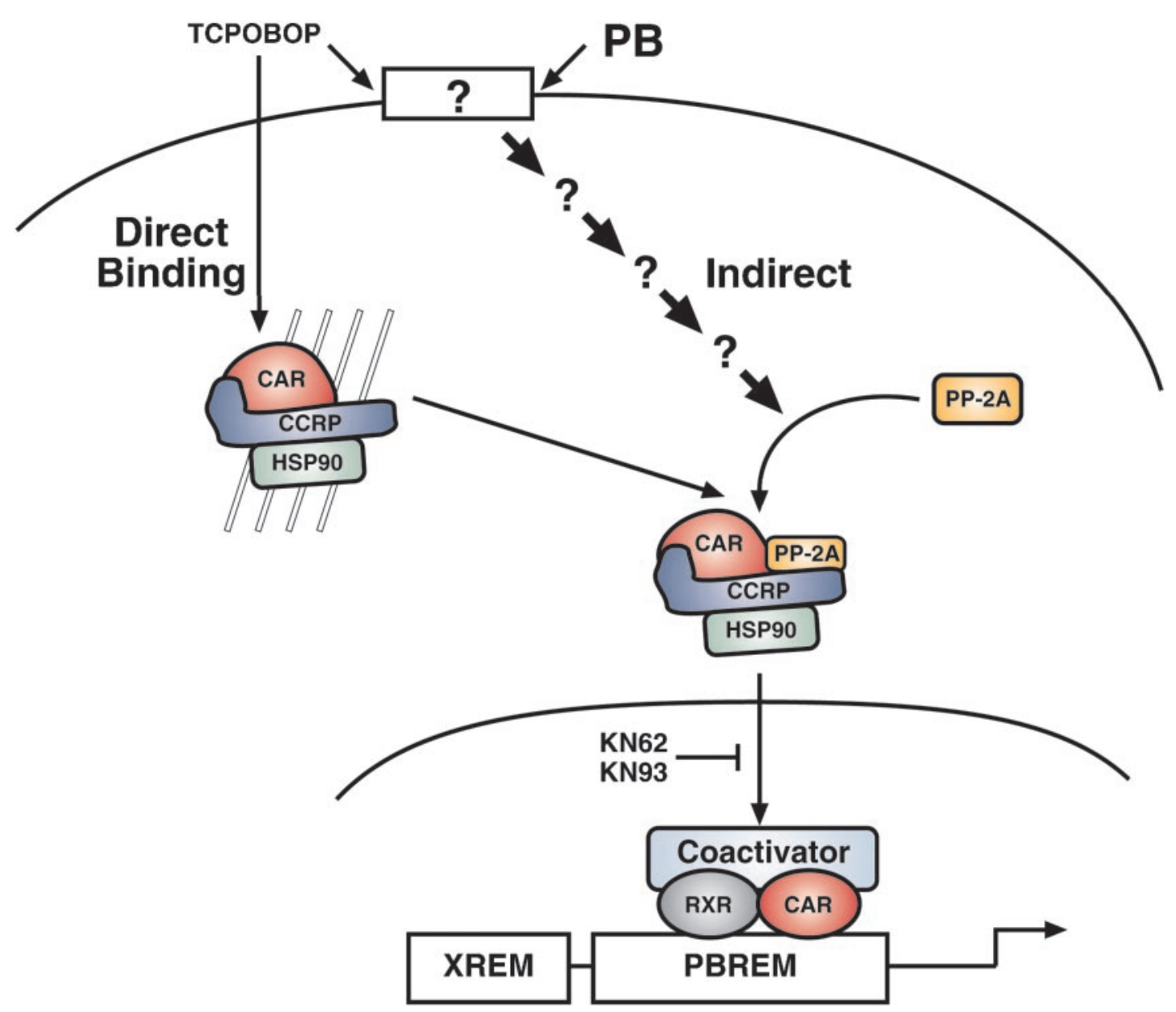

Fig. 2. Mechanism of CAR Activation

CAR translocation can be triggered by either direct ligand binding to the receptor, or indirectly, via a partially elucidated signal transduction pathway. CAR exists in a complex with Hsp90, retained in the cytoplasm by the cochaperone CCRP. Indirect activators or the direct binding of ligands to CAR subsequently recruits PP2A to the complex. Once in the nucleus, further activation steps involving calmodulin-dependent kinase and recruitment of coactivators occur before DNA binding and transcriptional activation of target genes.

of a single amino acid residue in CAR is able to alter a given specificity. Mutation of Thr350 in hormoneresponsive mouse CAR to methionine, as in nonresponsive human CAR, could abolish the repression by testosterone and progesterone and reactivation by estrogen (69). However, mutation of this residue did not change the repression of CAR activity by $\mathrm{Ca}^{2+} /$ calmodulin kinase inhibitor KN62, suggesting that the structural basis for hormone repression differs from that for repression by xenochemicals (69). In support of this hypothesis, only mutation of Leu352, a predicted key residue for AF2 interaction with coactivators, could abolish responsiveness to TCPOBOP and mutation of either residue Cys357 or Tyr336, which are proposed to interact with and stabilize helix 12, abolished the repressive effect of androstanol on transcriptional activity (70). Thus it appears that diverse CAR ligands interact with different residues to exert their effects, corresponding to the receptor's large LB cavity and predictions of alternate LB orientations $(48,60$,
61). Four naturally occurring in-frame splice variants of the human CAR gene compromise DNA binding, coactivator recruitment, and transcriptional activation, providing an additional source for functional variability and possible alternate interaction sites for those activators unable to bind directly to wild-type CAR (71). This promiscuous nature is reminiscent of CYP enzymes that exhibit broad substrate specificity yet determine a given activity by a single amino acid residue $(72,73)$. However, CAR is unique in the sense that activators do not necessarily directly bind to regulate CAR.

\section{NUCLEAR TRANSLOCATION MECHANISM}

\section{Ligand-Independent Translocation}

CAR is retained in the cytoplasm of untreated cells and translocates into the nuclei of liver cells after treatment 
with PB or PB-like inducers to activate PB-responsive genes (12) (Fig. 2). In contrast to steroid hormone receptors and $A h R$, which are triggered by direct $L B$, nuclear translocation of CAR does not require the direct binding of activators. Although $\mathrm{PB}$ does not bind directly to either mouse or human CAR, it translocates the receptors into the nucleus in mouse liver $(12,56)$. The potent PB-type activator TCPOBOP binds directly to mouse CAR (43) and translocates the receptor into the nucleus (12). On the other hand, human CAR does not bind TCPOBOP (43), yet is translocated after exposure to TCPOBOP when the receptor is expressed in the livers of wild-type mice (56). Therefore, activators can promote the nuclear translocation of CAR by a ligand-independent process, regardless of their receptor binding ability. Nuclear translocation of PXR appears to be regulated by a bipartite nuclear translocation signal (NLS) located in the DNA binding domain (74). In CAR, the nuclear import activity of the corresponding NLS seems to be weakened by mutations and thus does not regulate translocation (74). CAR lacking its AF2 domain translocated normally into the nucleus in mouse liver (56), whereas the translocation of the vitamin $D$ receptor and GR is dictated by the presence of their AF2 domains (Ref. 75 and Zelko, I., unpublished observations). In fact, deletion of the DNA binding domain or everything except the Cterminal half of the LB domain (residues 181-348) did not affect CAR nuclear translocation in mouse liver $(56,76)$. Thus, neither the AF2 domain nor a general NLS appeared to be involved in regulating CAR nuclear translocation. Instead, xenobiotic-responsive nuclear translocation activity was delineated to a leucine-rich peptide (L/MXXLXXL) distinct from the AF2 domain, named the xenobiotic response signal, within the $30 \mathrm{C}$-terminal residues of human and mouse CAR (56). Therefore, the regulatory mechanism underlying CAR nuclear translocation may be chemical-dependent activation of the xenobiotic response signal.

\section{Heat Shock Protein (Hsp)90 Complex and Protein Phosphatase 2A (PP2A)}

The CAR translocation process is sensitive to the protein phosphatase inhibitor okadaic acid, suggesting that it is regulated by a phosphorylation-dependent pathway (12). This signal transduction pathway has been confirmed by recent work demonstrating that a CAR-Hsp90 complex recruits PP2A upon treatment with PB (77). Before PB treatment, CAR exists as a complex with Hsp90 in the cytoplasm of noninduced mouse liver cells colocalized with microtubules (57, 77). As low concentrations of okadaic acid preferentially inhibit PP2A, it appears likely that PP2A recruitment leads CAR to translocate to the nucleus. Geldanamycin also inhibited the nuclear translocation of CAR by interrupting the chaperoning function of Hsp90, suggesting that it is also required for nuclear translocation (77).

\section{Cochaperone}

Whereas nuclear translocation occurs in the liver and in primary hepatocyte cultures via this signal transduction cascade, in transformed cell lines CAR accumulates spontaneously in the nucleus (12). This contrasts sharply with GR and AhR that are retained in the cytoplasm of hepatoma cells and translocate into the nucleus in response to agonists $(56,78)$. The cytoplasmic retention of GR and AhR relies on their formation of complexes with Hsp90 and cochaperones (79-81). We have now identified such a cochaperone for CAR, cytoplasmic CAR retention protein (CCRP), which retains the receptor in the cytoplasm when expressed in HepG2 cells (57). CCRP directly binds to CAR through the LB domain in a 1:1 molecular ratio and then mediates the binding of CAR to Hsp90 and the cytoplasmic accumulation of the complex in HepG2 cells (57). Tetratricopeptide repeat motifs, as found in CCRP, have been reported to recruit PP2A (82); therefore CCRP may be involved in the CAR-Hsp90-PP2A complex described by Yoshinari et al. (77).

\section{ACTIVATION PROCESS IN THE NUCLEUS}

Due to the correlation of nuclear translocation with target gene induction and the constitutive activity of CAR, it was believed initially that nuclear translocation led to the activation of CAR. However, our group has recently provided evidence to the contrary. The $\mathrm{Ca}^{2+}$ / calmodulin-dependent kinase inhibitor $\mathrm{KN}-62$ repressed induction of CYP2B10 mRNA as well as the activation of an NR1-reporter gene by both PB and TCPOBOP in mouse primary hepatocytes, but it did not prevent $\mathrm{PB}$-induced accumulation of CAR in the nuclei, suggesting that CAR may undergo a distinct activation process in the nucleus $(83,84)$. Retinoidrelated orphan receptor- $\alpha$, another constitutively activated nuclear orphan receptor, can be further activated by calmodulin-dependent kinase IV, although the receptor itself is not phosphorylated, and this activation is mediated by a small protein yet to be characterized (85). Because the versatile CAR regulates specific, yet diverse, functions, the activation mechanism remains enigmatic, although it may resemble, in part, the regulatory mechanism of retinoid-related orphan receptor- $\alpha$.

\section{COACTIVATORS}

An expanding number of coactivators and corepressors that interact with CAR have been identified, such as SRC-1 (14, 43, 62), GR-interacting protein 1 (86), Xenopus SRC-3 (87), and peroxisomal proliferatoractivated receptor- $\gamma$ coactivator $1 \alpha$ (88), which may simultaneously regulate CAR via different regions of 
the receptor. However, how they activate CAR in liver where the receptors' activity is tightly controlled has not been addressed directly. Whether peroxisomal proliferator-activated receptor- $\gamma$ coactivator $1 \alpha$, a socalled inducible coactivator, can also be a xenobioticresponsive coactivator and/or whether a yet unidentified coactivator may regulate CAR in response to xenobiotics is an urgent question for investigation. Although there are no reports on the role of coactivators on chromatin structure in CAR-mediated PB induction, evidence was provided recently, which suggests that the coactivators CAMP response element binding protein and CAMP response element binding protein-associated factor are recruited to a 556-bp enhancer region, similar to the PBREM, in the chicken CYP2H1 gene by chicken xenobiotic receptor after PB exposure. These coactivators acetylate the chromatin, allowing activation of the CYP2H1 promoter (89). As PB substantially alters chromatin structure in the PBresponsive unit and proximal promoter of CYP2B1/2 (90), it is likely that CAR also recruits coactivators with histone acetylase activity in mammals.

\section{CONCLUSION}

CAR has the potential to impact numerous signaling pathways via the genes it modulates directly and by its interference with other nuclear receptor signaling pathways. This creates a unique integrative mechanism to modulate the metabolism of not only xenobiotic substances but also endogenously produced steroids and dietary factors. Unlike its closest relative PXR, the function of which relies solely on ligand binding, CAR functions ligand independently and can be regulated by both direct ligand binding and indirect activation processes. In light of this, the elucidation of the mechanistic aspects of CAR regulation is extremely important to divulge the pathways involved and the evolutionary drive that separated CAR from PXR. Whereas much of the research into CAR regulation focuses on the effects of xenobiotics and in particular the unusual PB, which does not bind directly to CAR, we hope that this review has illustrated that the insights provided are equally applicable to the receptor's role in the metabolism of endogenous compounds. It now appears that the mechanism of CAR nuclear translocation and activation is much more complex and tightly regulated than initially believed and that exciting research in this area remains for the future.

\section{Acknowledgments}

We thank Rick Moore for the generation of novel data included in this review. We also thank Dr. Cary Weinberger and all members of the Pharmacogenetics section of the Laboratory of Reproductive and Developmental Toxicology, National Institute of Environmental Health Sciences, for their critical reading of the manuscript.
Received October 10, 2003. Accepted February 19, 2004. Address all correspondence and requests for reprints to: Dr. Masahiko Negishi, Pharmacogenetics Section, Laboratory of Reproductive and Developmental Toxicology, National Institute of Environmental Health Sciences, National Institutes of Health, Research Triangle Park, North Carolina 27709. E-mail: negishi@niehs.nih.gov.

\section{REFERENCES}

1. Baes M, Gulick T, Choi HS, Martinoli MG, Simha D, Moore DD 1994 A new orphan member of the nuclear hormone receptor superfamily that interacts with a subset of retinoic acid response elements. Mol Cell Biol 14:1544-1551

2. Choi HS, Chung M, Tzameli I, Simha D, Lee YK, Seol W, Moore DD 1997 Differential transactivation by two isoforms of the orphan nuclear hormone receptor CAR. J Biol Chem 272:23565-23571

3. Honkakoski P, Moore R, Washburn KA, Negishi M 1998 Activation by diverse xenochemicals of the 51-base pair phenobarbital-responsive enhancer module in the CYP2B10 gene. Mol Pharmacol 53:597-601

4. Honkakoski P, Zelko I, Sueyoshi T, Negishi M 1998 The nuclear orphan receptor CAR-retinoid $X$ receptor heterodimer activates the phenobarbital-responsive enhancer module of the CYP2B gene. Mol Cell Biol 18: 5652-5658

5. Sueyoshi T, Kawamoto T, Zelko I, Honkakoski P, Negish M 1999 The repressed nuclear receptor CAR responds to phenobarbital in activating the human CYP2B6 gene. J Biol Chem 274:6043-6046

6. Wei P, Zhang J, Egan-Hafley M, Liang S, Moore DD 2000 The nuclear receptor CAR mediates specific xenobiotic induction of drug metabolism. Nature 407:920-923

7. Ueda A, Hamadeh HK, Webb HK, Yamamoto Y, Sueyoshi T, Afshari CA, Lehmann JM, Negishi M 2002 Diverse roles of the nuclear orphan receptor CAR in regulating hepatic genes in response to phenobarbital. Mol Pharmacol 61:1-6

8. Maglich JM, Stoltz CM, Goodwin B, Hawkins-Brown D, Moore JT, Kliewer SA 2002 Nuclear pregnane x receptor and constitutive androstane receptor regulate overlapping but distinct sets of genes involved in xenobiotic detoxification. Mol Pharmacol 62:638-646

9. Wei P, Zhang J, Dowhan DH, Han Y, Moore DD 2002 Specific and overlapping functions of the nuclear hormone receptors CAR and PXR in xenobiotic response. Pharmacogenomics $\mathrm{J}$ 2:117-126

10. Honkakoski P, Sueyoshi T, Negishi M 2003 Drug-activated nuclear receptors CAR and PXR. Ann Med 35: 172-182

11. Rosenfeld JM, Vargas Jr R, Xie W, Evans RM 2003 Genetic profiling defines the xenobiotic gene network controlled by the nuclear receptor PXR. Mol Endocrinol 17: 1268-1282

12. Kawamoto T, Sueyoshi T, Zelko I, Moore R, Washburn K, Negishi M 1999 Phenobarbital-responsive nuclear translocation of the receptor CAR in induction of the CYP2B gene. Mol Cell Biol 19:6318-6322

13. Sueyoshi T, Negishi M 2001 Phenobarbital response elements of cytochrome P450 genes and nuclear receptors. Annu Rev Pharmacol Toxicol 41:123-143

14. Forman BM, Tzameli I, Choi HS, Chen J, Simha D, Seol W, Evans RM, Moore DD 1998 Androstane metabolites bind to and deactivate the nuclear receptor CAR- $\beta$. Nature 395:612-615

15. Nuclear Receptors Nomenclature Committee 1999 A unified nomenclature system for the nuclear receptor superfamily. Cell 97:161-163 
16. Blumberg B, Sabbagh Jr W, Juguilon H, Bolado Jr J, van Meter CM, Ong ES, Evans RM 1998 SXR, a novel steroid and xenobiotic-sensing nuclear receptor. Genes Dev 12: 3195-3205

17. Kliewer SA, Moore JT, Wade L, Staudinger JL, Watson MA, Jones SA, McKee DD, Oliver BB, Willson TM, Zetterstrom RH, Perlmann T, Lehmann JM 1998 An orphan nuclear receptor activated by pregnanes defines a novel steroid signaling pathway. Cell 92:73-82

18. Xie W, Barwick JL, Downes M, Blumberg B, Simon CM, Nelson MC, Neuschwander-Tetri BA, Brunt EM, Guzelian PS, Evans RM 2000 Humanized xenobiotic response in mice expressing nuclear receptor SXR. Nature 406: 435-439

19. Handschin C, Podvinec M, Meyer UA 2000 CXR, a chicken xenobiotic-sensing orphan nuclear receptor, is related to both mammalian pregnane $\mathrm{X}$ receptor (PXR) and constitutive androstane receptor (CAR). Proc Natl Acad Sci USA 97:10769-10774

20. Lindblom TH, Pierce GJ, Sluder AE 2001 A C. elegans orphan nuclear receptor contributes to xenobiotic resistance. Curr Biol 11:864-868

21. Blumberg B, Kang H, Bolado Jr J, Chen H, Craig AG, Moreno TA, Umesono K, Perlmann T, De Robertis EM, Evans RM 1998 BXR, an embryonic orphan nuclear receptor activated by a novel class of endogenous benzoate metabolites. Genes Dev 12:1269-1277

22. Maglich JM, Caravella JA, Lambert MH, Willson TM, Moore JT, Ramamurthy L 2003 The first completed genome sequence from a teleost fish (Fugu rubripes) adds significant diversity to the nuclear receptor superfamily. Nucleic Acids Res 31:4051-4058

23. Fisk GJ, Thummel CS 1995 Isolation, regulation, and DNA-binding properties of three Drosophila nuclear hormone receptor superfamily members. Proc Natl Acad Sci USA 92:10604-10608

24. Sugatani J, Kojima H, Ueda A, Kakizaki S, Yoshinari K, Gong QH, Owens IS, Negishi M, Sueyoshi T 2001 The phenobarbital response enhancer module in the human bilirubin UDP-glucuronosyltransferase UGT1A1 gene and regulation by the nuclear receptor CAR. Hepatology 33:1232-1238

25. Huang W, Zhang J, Chua SS, Qatanani M, Han Y, Granata R, Moore DD 2003 Induction of bilirubin clearance by the constitutive androstane receptor (CAR). Proc Natl Acad Sci USA 100:4156-4161

26. Xie W, Yeuh MF, Radominska-Pandya A, Saini SP, Negishi Y, Bottroff BS, Cabrera GY, Tukey RH, Evans RM 2003 Control of steroid, heme, and carcinogen metabolism by nuclear pregnane $X$ receptor and constitutive androstane receptor. Proc Natl Acad Sci USA 100: 4150-4155

27. Yueh MF, Huang YH, Hiller A, Chen S, Nguyen N, Tukey $\mathrm{RH} 2003$ Involvement of the xenobiotic response element (XRE) in Ah receptor-mediated induction of human UDP-glucuronosyltransferase 1A1. J Biol Chem 278: 15001-15006

28. Kast HR, Goodwin B, Tarr PT, Jones SA, Anisfeld AM, Stoltz CM, Tontonoz P, Kliewer S, Willson TM, Edwards PA 2002 Regulation of multidrug resistance-associated protein 2 (ABCC2) by the nuclear receptors pregnane $X$ receptor, farnesoid X-activated receptor, and constitutive androstane receptor. J Biol Chem 277:2908-2915

29. Courtois A, Payen L, Le Ferrec E, Scheffer GL, Trinquart Y, Guillouzo A, Fardel O 2002 Differential regulation of multidrug resistance-associated protein 2 (MRP2) and cytochromes P450 2B1/2 and 3A1/2 in phenobarbitaltreated hepatocytes. Biochem Pharmacol 63:333-341

30. Johnson DR, Klaassen CD 2002 Regulation of rat multidrug resistance protein 2 by classes of prototypical microsomal enzyme inducers that activate distinct transcription pathways. Toxicol Sci 67:182-189
31. Xiong H, Yoshinari K, Brouwer KL, Negishi M 2002 Role of constitutive androstane receptor in the in vivo induction of Mrp3 and CYP2B1/2 by phenobarbital. Drug Metab Dispos 30:918-923

32. Guo GL, Lambert G, Negishi M, Ward JM, Brewer Jr HB, Kliewer SA, Gonzalez FJ, Sinal CJ 2003 Complementary roles of farnesoid $\mathrm{X}$ receptor, pregnane $\mathrm{X}$ receptor, and constitutive androstane receptor in protection against bile acid toxicity. J Biol Chem 278:45062-45071

33. Zhang J, Huang W, Chua SS, Wei P, Moore DD 2002 Modulation of acetaminophen-induced hepatotoxicity by the xenobiotic receptor CAR. Science 298:422-424

34. Morel F, Fardel O, Meyer DJ, Langouet S, Gilmore KS, Meunier B, Tu CP, Kensler TW, Ketterer B, Guillouzo A 1993 Preferential increase of glutathione S-transferase class $\alpha$ transcripts in cultured human hepatocytes by phenobarbital, 3-methylcholanthrene, and dithiolethiones. Cancer Res 53:231-234

35. Hayes JD, Pulford DJ 1995 The glutathione S-transferase supergene family: regulation of GST and the contribution of the isoenzymes to cancer chemoprotection and drug resistance. Crit Rev Biochem Mol Biol 30:445-600

36. Henderson CJ, Wolf CR, Kitteringham N, Powell H, Otto D, Park BK 2000 Increased resistance to acetaminophen hepatotoxicity in mice lacking glutathione S-transferase Pi. Proc Natl Acad Sci USA 97:12741-12745

37. Toell A, Kroncke KD, Kleinert H, Carlberg C 2002 Orphan nuclear receptor binding site in the human inducible nitric oxide synthase promoter mediates responsiveness to steroid and xenobiotic ligands. J Cell Biochem 85:72-82

38. Honkakoski P, Moore R, Gynther J, Negishi M 1996 Characterization of phenobarbital-inducible mouse Cyp2b10 gene transcription in primary hepatocytes. J Biol Chem 271:9746-9753

39. Doherty MM, Charman WN 2002 The mucosa of the small intestine: how clinically relevant as an organ of drug metabolism? Clin Pharmacokinet 41:235-253

40. Kawamoto T, Kakizaki S, Yoshinari K, Negishi M 2000 Estrogen activation of the nuclear orphan receptor CAR (constitutive active receptor) in induction of the mouse Cyp2b10 gene. Mol Endocrinol 14:1897-1905

41. Bartke A, Steele RE, Musto N, Caldwell BV 1973 Fluctuations in plasma testosterone levels in adult male rats and mice. Endocrinology 92:1223-1228

42. Bicknell DC, Gower DB 1976 The development and application of a radioimmunoassay for $5 \alpha$-androst-16-en$3 \alpha$-ol in plasma. J Steroid Biochem 7:451-455

43. Moore LB, Parks DJ, Jones SA, Bledsoe RK, Consler TG, Stimmel JB, Goodwin B, Liddle C, Blanchard SG, Willson TM, Collins JL, Kliewer SA 2000 Orphan nuclear receptors constitutive androstane receptor and pregnane $X$ receptor share xenobiotic and steroid ligands. J Biol Chem 275:15122-15127

44. Ledda-Columbano GM, Pibiri M, Concas D, Molotzu F, Simbula G, Cossu C, Columbano A 2003 Sex difference in the proliferative response of mouse hepatocytes to treatment with the CAR ligand, TCPOBOP. Carcinogenesis 24:1059-1065

45. Senafi SB, Clarke DJ, Burchell B 1994 Investigation of the substrate specificity of a cloned expressed human bilirubin UDP-glucuronosyltransferase: UDP-sugar specificity and involvement in steroid and xenobiotic glucuronidation. Biochem J 303:233-240

46. Tukey RH, Strassburg CP 2000 Human UDPglucuronosyltransferases: metabolism, expression, and disease. Annu Rev Pharmacol Toxicol 40:581-616

47. Raftogianis R, Creveling C, Weinshilboum R, Weisz J 2000 Estrogen metabolism by conjugation. J Natl Cancer Inst Monogr 27:113-124

48. Maglich JM, Parks DJ, Moore LB, Collins JL, Goodwin B, Billin AN, Stoltz CA, Kliewer SA, Lambert MH, Willson TM, Moore JT 2003 Identification of a novel human constitutive androstane receptor (CAR) agonist and its use in 
the identification of CAR target genes. J Biol Chem 278: 17277-17283

49. Negishi M, Pedersen LG, Petrotchenko E, Shevtsov S, Gorokhov A, Kakuta Y, Pedersen LC 2001 Structure and function of sulfotransferases. Arch Biochem Biophys 390:149-157

50. Pascussi JM, Busson-Le Coniat M, Maurel P, Vilarem MJ 2003 Transcriptional analysis of the orphan nuclear receptor constitutive androstane receptor (NR1/3) gene promoter: identification of a distal glucocorticoid response element. Mol Endocrinol 17:42-55

51. Pascussi JM, Gerbal-Chaloin S, Fabre JM, Maurel P, Vilarem MJ 2000 Dexamethasone enhances constitutive androstane receptor expression in human hepatocytes: consequences on cytochrome $\mathrm{P} 450$ gene regulation. $\mathrm{Mol}$ Pharmacol 58:1441-1450

52. Pascussi JM, Drocourt L, Gerbal-Chaloin S, Fabre JM, Maurel P, Vilarem MJ 2001 Dual effect of dexamethasone on CYP3A4 gene expression in human hepatocytes. Sequential role of glucocorticoid receptor and pregnane X receptor. Eur J Biochem 268:6346-6358

53. Shaw PM, Adesnik M, Weiss MC, Corcos L 1993 The phenobarbital-induced transcriptional activation of cytochrome P-450 genes is blocked by the glucocorticoidprogesterone antagonist RU486. Mol Pharmacol 44: 775-783

54. Honkakoski P, Negishi M 1998 Regulatory DNA elements of phenobarbital-responsive cytochrome P450 CYP2B genes. J Biochem Mol Toxicol 12:3-9

55. Schuetz EG, Schmid W, Schutz G, Brimer C, Yasuda K, Kamataki T, Bornheim L, Myles K, Cole TJ 2000 The glucocorticoid receptor is essential for induction of cytochrome P-4502B by steroids but not for drug or steroid induction of CYP3A or P-450 reductase in mouse liver. Drug Metab Dispos 28:268-278

56. Zelko I, Sueyoshi T, Kawamoto T, Moore R, Negishi M 2001 The peptide near the $C$ terminus regulates receptor CAR nuclear translocation induced by xenochemicals in mouse liver. Mol Cell Biol 21:2838-2846

57. Kobayashi K, Sueyoshi T, Inoue K, Moore R, Negishi M 2003 Cytoplasmic accumulation of the nuclear receptor CAR by a tetratricopeptide repeat protein in HepG2 cells. Mol Pharmacol 64:1069-1075

58. Dussault I, Lin M, Hollister K, Fan M, Termini J, Sherman MA, Forman BM 2002 A structural model of the constitutive androstane receptor defines novel interactions that mediate ligand-independent activity. Mol Cell Biol 22: $5270-5280$

59. Moore LB, Maglich JM, McKee DD, Wisely B, Willson TM, Kliewer SA, Lambert MH, Moore JT 2002 Pregnane $X$ receptor (PXR), constitutive androstane receptor $(C A R)$, and benzoate $X$ receptor (BXR) define three pharmacologically distinct classes of nuclear receptors. Mol Endocrinol 16:977-986

60. Xiao L, Cui X, Madison V, White RE, Cheng KC 2002 Insights from a three-dimensional model into ligand binding to constitutive active receptor. Drug Metab Dispos 30:951-956

61. Jacobs MN, Dickins M, Lewis DF 2003 Homology modelling of the nuclear receptors: human oestrogen recep$\operatorname{tor} \beta$ (hER $\beta$ ), the human pregnane-X-receptor (PXR), the Ah receptor (AhR) and the constitutive androstane receptor (CAR) ligand binding domains from the human oestrogen receptor $\alpha(\mathrm{hER} \alpha)$ crystal structure, and the human peroxisome proliferator activated receptor $\alpha$ (PPAR $\alpha$ ) ligand binding domain from the human PPAR $\gamma$ crystal structure. J Steroid Biochem Mol Biol 84:117-132

62. Muangmoonchai R, Smirlis D, Wong SC, Edwards M, Phillips IR, Shephard EA 2001 Xenobiotic induction of cytochrome P450 2B1 (CYP2B1) is mediated by the orphan nuclear receptor constitutive androstane receptor (CAR) and requires steroid co-activator 1 (SRC-1) and the transcription factor Sp1. Biochem J 355:71-78
63. Dhe-Paganon S, Duda K, Iwamoto M, Chi YI, Shoelson SE 2002 Crystal structure of the HNF $4 \alpha$ ligand binding domain in complex with endogenous fatty acid ligand. J Biol Chem 277:37973-37976

64. Greschik H, Wurtz JM, Sanglier S, Bourguet W, van Dorsselaer A, Moras D, Renaud JP 2002 Structural and functional evidence for ligand-independent transcriptional activation by the estrogen-related receptor 3 . Mol Cell 9:303-313

65. Wisely GB, Miller AB, Davis RG, Thornquest Jr AD, Johnson R, Spitzer T, Sefler A, Shearer B, Moore JT, Willson TM, Williams SP 2002 Hepatocyte nuclear factor 4 is a transcription factor that constitutively binds fatty acids. Structure (Camb) 10:1225-1234

66. Baker KD, Shewchuk LM, Kozlova T, Makishima M, Hassell A, Wisely B, Caravella JA, Lambert MH, Reinking JL, Krause $\mathrm{H}$, Thummel CS, Willson TM, Mangelsdorf DJ 2003 The Drosophila orphan nuclear receptor DHR38 mediates an atypical ecdysteroid signaling pathway. Cell 113:731-742

67. Sablin EP, Krylova IN, Fletterick RJ, Ingraham HA 2003 Structural basis for ligand-independent activation of the orphan nuclear receptor LRH-1. Mol Cell 11:1575-1585

68. Wang Z, Benoit G, Liu J, Prasad S, Aarnisalo P, Liu X, Xu $\mathrm{H}$, Walker NP, Perlmann T 2003 Structure and function of Nurr1 identifies a class of ligand-independent nuclear receptors. Nature 423:555-560

69. Ueda A, Kakizaki S, Negishi M, Sueyoshi T 2002 Residue threonine 350 confers steroid hormone responsiveness to the mouse nuclear orphan receptor CAR. Mol Pharmacol 61:1284-1288

70. Andersin T, Vaisanen S, Carlberg C 2003 The critical role of carboxy-terminal amino acids in ligand-dependent and -independent transactivation of the constitutive androstane receptor. Mol Endocrinol 17:234-246

71. Auerbach SS, Ramsden R, Stoner MA, Verlinde C, Hassett C, Omiecinski CJ 2003 Alternatively spliced isoforms of the human constitutive androstane receptor. Nucleic Acids Res 31:3194-3207

72. Lindberg RL, Negishi M 1989 Alteration of mouse cytochrome P450coh substrate specificity by mutation of a single amino-acid residue. Nature 339:632-634

73. Negishi M, Uno T, Darden TA, Sueyoshi T, Pedersen LG 1996 Structural flexibility and functional versatility of mammalian P450 enzymes. FASEB J 10:683-689

74. Kawana K, Ikuta T, Kobayashi Y, Gotoh O, Takeda K, Kawajiri K 2003 Molecular mechanism of nuclear translocation of an orphan nuclear receptor, SXR. Mol Pharmacol 63:524-531

75. Racz A, Barsony J 1999 Hormone-dependent translocation of vitamin $D$ receptors is linked to transactivation. J Biol Chem 274:19352-19360

76. Sueyoshi T, Moore R, Pascussi JM, Negishi M 2002 Direct expression of fluorescent protein-tagged nuclear receptor CAR in mouse liver. Methods Enzymol 357: 205-213

77. Yoshinari K, Kobayashi K, Moore R, Kawamoto T, Negishi M 2003 Identification of the nuclear receptor CAR: HSP90 complex in mouse liver and recruitment of protein phosphatase $2 \mathrm{~A}$ in response to phenobarbital. FEBS Lett 548:17-20

78. Pollenz RS, Sattler CA, Poland A 1994 The aryl hydrocarbon receptor and aryl hydrocarbon receptor nuclear translocator protein show distinct subcellular localizations in Hepa 1c1c7 cells by immunofluorescence microscopy. Mol Pharmacol 45:428-438

79. Kazlauskas A, Poellinger L, Pongratz I 2000 The immunophilin-like protein XAP2 regulates ubiquitination and subcellular localization of the dioxin receptor. J Biol Chem 275:41317-41324

80. Kazlauskas A, Sundstrom S, Poellinger L, Pongratz I 2001 The hsp90 chaperone complex regulates intracel- 
Iular localization of the dioxin receptor. Mol Cell Biol 21:2594-2607

81. Davies TH, Ning YM, Sanchez ER 2002 A new first step in activation of steroid receptors: hormone-induced switching of FKBP51 and FKBP52 immunophilins. J Biol Chem 277:4597-4600

82. Srinivasan A, McClellan AJ, Vartikar J, Marks I, Cantalupo P, Li Y, Whyte P, Rundell K, Brodsky JL, Pipas JM 1997 The amino-terminal transforming region of simian virus 40 large $\mathrm{T}$ and small $\mathrm{t}$ antigens functions as a $\mathrm{J}$ domain. Mol Cell Biol 17:4761-4773

83. Marc N, Galisteo M, Lagadic-Gossmann D, Fautrel A, Joannard F, Guillouzo A, Corcos L 2000 Regulation of phenobarbital induction of the cytochrome P450 2b9/10 genes in primary mouse hepatocyte culture. Involvement of calcium- and cAMP-dependent pathways. Eur J Biochem 267:963-970

84. Yamamoto Y, Kawamoto T, Negishi M 2003 The role of the nuclear receptor CAR as a coordinate regulator of hepatic gene expression in defense against chemical toxicity. Arch Biochem Biophys 409:207-211

85. Kane CD, Means AR 2000 Activation of orphan receptormediated transcription by $\mathrm{Ca}(2+) /$ calmodulin-dependent protein kinase IV. EMBO J 19:691-701
86. Min G, Kemper JK, Kemper B 2002 Glucocorticoid receptor-interacting protein 1 mediates ligand-independent nuclear translocation and activation of constitutive androstane receptor in vivo. J Biol Chem 277: 26356-26363

87. Kim HJ, Lee SK, Na SY, Choi HS, Lee JW 1998 Molecular cloning of XSRC-3, a novel transcription coactivator from Xenopus, that is related to AlB1, p/CIP, and TIF2. Mol Endocrinol 12:1038-1047

88. Shiraki T, Sakai N, Kanaya E, Jingami H 2003 Activation of orphan nuclear constitutive androstane receptor requires subnuclear targeting by peroxisome proliferatoractivated receptor $\gamma$ coactivator-1 $\alpha$. A possible link between xenobiotic response and nutritional state. J Bio Chem 278:11344-11350

89. Dogra SC, Tremethick D, May BK 2003 Evidence that the coactivator CBP/p300 is important for phenobarbitalinduced but not basal expression of the CYP2H1 gene. Mol Pharmacol 63:73-80

90. Kim J, Rivera-Rivera I, Kemper B 2000 Tissue-specific chromatin structure of the phenobarbital-responsive unit and proximal promoter of CYP2B1/2 and modulation by phenobarbital. Nucleic Acids Res 28:1126-1132 